CLINICAL STUDY

\title{
Healthcare utilization, quality of life and patient-reported outcomes during two years of GH replacement therapy in GH-deficient adults - comparison between Sweden, The Netherlands and Germany
}

\author{
Bernhard Saller, Anders F Mattsson ${ }^{1}$, Peter H Kann ${ }^{2 *}$, Hans P Koppeschaar ${ }^{3 \dagger}$, Johan Svensson ${ }^{4 \ddagger}$, \\ Marjolein Pompen ${ }^{5 \dagger}$ and Maria Koltowska-Häggström ${ }^{1}$ \\ Medical Department, Pfizer GmbH, Karlsruhe, Karlsruhe, Germany, ${ }^{1}$ KIGS/KIMS/ACROSTUDY Medical Outcomes, Pfizer Endocrine Care, Sollentuna, \\ Sweden, ${ }^{2}$ Divison of Endocrinology \& Diabetology, University Hospital Giessen and Marburg, Philipps University Marburg, Marburg, Germany, \\ ${ }^{3}$ Department of Endocrinology, University Medical Center Utrecht, Utrecht, Utrecht, The Netherlands, ${ }^{4}$ Research Centre for Endocrinology and \\ Metabolism, Sahlgrenska University Hospital, Goteborg, Goteborg, Sweden, ${ }^{5}$ Medical Department, Pfizer BV, Capelle a/d IJssel, Capelle a/d IJssel, \\ The Netherlands
}

${ }^{*}$ On behalf of the German KIMS investigators; $†$ On behalf of the Dutch KIMS investigators; $\ddagger$ On behalf of the Swedish KIMS investigators.

(Correspondence should be addressed to B Saller; EndoScience Endokrinologie Service GmbH. Thalkirchner Str. 1, 80337 Munich, Germany; Email: saller@endoscience.de)

\begin{abstract}
Objective: This study set out to determine the change in quality of life (QoL) and healthcare utilization during 2 years of growth hormone $(\mathrm{GH})$ replacement therapy in adults with GH deficiency. Data were compared from three European countries.

Design: Analysis was made from KIMS, the Pfizer International Metabolic Database on adult GH deficiency.

Methods: QoL and healthcare utilization were measured at baseline and after 1 and 2 years of GH replacement in patient cohorts from Sweden $(n=302)$, The Netherlands $(n=103)$ and Germany $(n=98)$. QoL was assessed by the QoL-Assessment in Growth Hormone Deficient Adults (QoL-AGHDA) questionnaire, and the KIMS Patient Life Situation Form was used to evaluate healthcare utilization.

Results: QoL improved significantly $(P<0.0001)$ and comparably in all three cohorts. The improvement was seen during the first year of treatment and QoL remained improved during the second year. The number of days in hospital was reduced by $83 \%(P<0.0001)$ during GH replacement. There were no country-specific differences either at baseline or during follow-up. The same was true for the number of days of sick leave (reduction of $63 \% ; P=0.0004$ ). Significant reductions were recorded in the number of doctor visits in each of the three cohorts after 2 years of GH replacement $(P<0.05)$.

Conclusions: This study provides a detailed comparative analysis of GH replacement therapy in GHD patients in three European countries. Despite some differences in treatment strategies, the beneficial effects on QoL, patient-reported outcomes and healthcare utilization are essentially similar in the healthcare environment of Western European countries.
\end{abstract}

European Journal of Endocrinology 154 843-850

\section{Introduction}

The beneficial clinical effects of growth hormone (GH) replacement therapy in hypopituitary adults with $\mathrm{GH}$ deficiency (GHD) have been established from numerous clinical trials (1-13). Data are also available from KIMS the Pfizer International Metabolic Database - a large pharmacoepidemiological survey started in 1994 to look at the long-term safety and outcomes of GH replacement therapy with Genotropin in adults with GHD.
This database contains comprehensive clinical information on more than 10,000 hypopituitary adults with GHD from 28 countries. The database has confirmed the efficacy of GH replacement, including improvements in well-being and quality of life (QoL), which have previously been shown by Hernberg-Ståhl et al. to be accompanied by a reduction in healthcare utilization (14). That study was based on patient data from a wide range of countries with different healthcare environments. As socioeconomic evaluations depend on the 
particular system of healthcare employed by different countries, analysis of country-specific data is necessary before results can be used for further health-economic evaluations. Such a single-country analysis, from Sweden (15), confirmed the previous multinational findings (14).

The aim of the present study was to investigate and compare the effect of GH replacement on QoL, patientreported health outcomes and healthcare utilization in Sweden, The Netherlands and Germany, and to analyse whether changes in QoL scores correlate with changes in patient-reported outcomes and healthcare utilization. There are similarities between the three countries with respect to their cultural background, their healthcare policy as well as the approval and reimbursement criteria for $\mathrm{GH}$ replacement therapy in hypopituitary adults.

\section{Subjects and methods}

\section{Patients}

The study was based on data from 503 patients with GHD due to pituitary or hypothalamic disease, who were consecutively enrolled in KIMS in Sweden $(n=302)$, The Netherlands $(n=103)$ and Germany $(n=98)$. Diagnosis of GHD was based on a GH peak $<3 \mu \mathrm{g} / \mathrm{l}$ in well-accepted $\mathrm{GH}$ stimulation tests. Indication for GH replacement therapy was at the discretion of the responsible physician. Local approval and reimbursement criteria were similar for the three countries and do require proven GHD in the presence of hypopituitary or hypothalamic disease.

Inclusion criteria for the study included GH replacement therapy for at least 2 years and the absence of treatment with GH before inclusion in KIMS. The baseline characteristics of the patient populations, together with the causes of GHD, are given in Table 1.

The majority of patients had multiple pituitary hormone deficiencies, and were receiving standard hormone replacement therapy (Table 2). Interestingly, the percentage of women receiving estrogen replacement was essentially different between the three countries, ranging from $21 \%$ in The Netherlands to $54 \%$ in Germany. The percentages of other replaced hormones were similar.

\section{Assessments}

Healthcare utilization and QoL were assessed by selfadministered questionnaires at baseline and after 1 and 2 years of GH replacement therapy.

Quality of life. QoL was evaluated by the QoLAssessment in Growth Hormone Deficient Adults (QoL-AGHDA) questionnaire. The QoL-AGHDA has been developed as a disease-specific instrument for the detection of deficits in areas that are affected in adults

Table 1 Baseline characteristics of $503 \mathrm{GH}$-deficient adults enrolled in KIMS - the Pfizer International Metabolic Database - in Sweden, The Netherlands and Germany. Values are means \pm s.D. or 10th to 90th percentiles unless indicated otherwise.

\begin{tabular}{|c|c|c|c|}
\hline & Swedish cohort $(n=302)$ & Dutch cohort $(n=103)$ & German cohort $(n=98)$ \\
\hline Age at enrolment (years) & $51.1 \pm 12.8$ & $46.6 \pm 13.5$ & $46.7 \pm 13.3$ \\
\hline Males/females & $151 / 151$ & $50 / 53$ & $57 / 41$ \\
\hline Body mass index $\left(\mathrm{kg} / \mathrm{m}^{2}\right)$ & $27.5 \pm 4.9$ & $27.7 \pm 4.3$ & $27.6 \pm 5.2$ \\
\hline \multicolumn{4}{|l|}{ Cause of GH deficiency } \\
\hline Pituitary adenoma & $202(66.9 \%)$ & $61(59.2 \%)$ & $55(56.1 \%)$ \\
\hline Craniopharyngioma & $22(7.3 \%)$ & $7(6.8 \%)$ & $15(15.3 \%)$ \\
\hline $\begin{array}{l}\text { Other pituitary/hypothalamic } \\
\text { tumours }\end{array}$ & $9(3.0 \%)$ & $9(8.7 \%)$ & $5(5.1 \%)$ \\
\hline $\begin{array}{l}\text { Non-pituitary, non-hypothala- } \\
\text { mic cranial tumours }\end{array}$ & $8(2.6 \%)$ & $4(3.9 \%)$ & $2(2.0 \%)$ \\
\hline $\begin{array}{l}\text { Treatment for malignancy out- } \\
\text { side the cranium }\end{array}$ & $0(0.0 \%)$ & $4(3.9 \%)$ & $0(0.0 \%)$ \\
\hline Idiopathic GH deficiency & $26(8.6 \%)$ & $5(4.9 \%)$ & $11(11.2 \%)$ \\
\hline Other causes & $35(11.6 \%)$ & $13(12.6 \%)$ & $10(10.2 \%)$ \\
\hline Adult-onset $\mathrm{GH}$ deficiency* & $283(93.7 \%)$ & $91(88.3 \%)$ & $95(96.9 \%)$ \\
\hline Isolated GH deficiency ${ }^{*}$ & $25(8.3 \%)$ & $15(14.6 \%)$ & $4(4.1 \%)$ \\
\hline $\begin{array}{l}\text { Time since diagnosis of pituitary } \\
\text { disease (years) }\end{array}$ & $10(1.3-23.3)$ & $9.4(1.2-22.5)$ & $7.2(1.1-7.7)$ \\
\hline $\begin{array}{l}\text { Time since diagnosis of } \mathrm{GH} \\
\text { deficiency (years) }\end{array}$ & $1.5(0.2-2.7)$ & $2.0(0.2-5.3)$ & $1.9(0-5.2)$ \\
\hline Pituitary surgery performed & 207 (68.5\%) & $72(69.9 \%)$ & $71(72.4 \%)$ \\
\hline $\begin{array}{l}\text { Time since last pituitary surgery } \\
\text { (years) }\end{array}$ & $7.7(0.0-20)$ & $8.2(2-18)$ & $5.6(0-16)$ \\
\hline Radiotherapy performed ${ }^{\star \star *}$ & $113(37.4 \%)$ & $57(55.3 \%)$ & $7(7.1 \%)$ \\
\hline $\begin{array}{l}\text { Time since last radiotherapy } \\
\text { (years) }\end{array}$ & $12.6(2-24)$ & $9.4(0-20)$ & $9.4(2-32)$ \\
\hline
\end{tabular}

${ }^{\star} P<0.05,{ }^{* \star} P<0.01,{ }^{* \star \star} P<0.001$ for heterogeneity between countries. 
Table 2 Hormone replacement therapy in addition to GH replacement in adult GH-deficient patients enrolled in KIMS - the Pfizer International Metabolic Database - in Sweden, The Netherlands and Germany.

\begin{tabular}{|c|c|c|c|}
\hline \multirow[b]{2}{*}{ Hormone substituted } & \multicolumn{3}{|c|}{ Number of patients } \\
\hline & Sweden & The Netherlands & Germany \\
\hline \multicolumn{4}{|l|}{ Sex steroids } \\
\hline Males (testosterone) & $134(88.7 \%)$ & $34(68.0 \%)$ & $50(87.7 \%)$ \\
\hline Females (oestrogens) & $68(45.0 \%)$ & $11(20.8 \%)$ & $22(53.6 \%)$ \\
\hline Hydrocortisone & $210(69.6 \%)$ & $68(66.0 \%)$ & 78 (79.6\%) \\
\hline Thyroid hormone & $246(81.5 \%)$ & $75(72.8 \%)$ & $71(72.4 \%)$ \\
\hline Antidiuretic hormone & 61 (20.2\%) & 20 (19.4\%) & $25(25.5 \%)$ \\
\hline
\end{tabular}

with GHD (16). The questionnaire consists of 25 questions with 'yes' or 'no' answers, a 'yes' answer indicating that the patient perceives a problem. The sum of the number of 'yes' answers is used as a measure of QoL, with a high score denoting an impaired QoL.

From the three countries included in the analysis, reference data for QoL-AGHDA in the general population are available for Sweden with a mean score adjusted to age 50 of $3.8(17,18)$.

Patients' personal situations. The KIMS Patient Life Situation Form was used to record each patient's personal situation (marital status, education, employment and other data) and use of social care and healthcare resources. At the baseline visit, the patients were asked about number of days of sick leave, number of days in hospital and number of visits to a doctor, other than routine endocrine visits, during the last 6 months before entry into KIMS. At the follow-up visits, patients completed the same questionnaire for the period since their last visit. Analyses of sick leave have been performed only for patients at work and for students.

Patient-reported outcomes. Each patient's perception of treatment since their last visit was recorded using a five-point scale, where 1 corresponds to the answer 'I feel much improved', and 5 corresponds to the answer 'I feel much worse'.

$\mathrm{P} \backslash$ kern-2pthysical activity during leisure time and satisfaction with that physical activity were measured using a visual analogue scale (VAS). High numerical values indicate high levels of physical activity and a greater degree of satisfaction. The need for assistance with daily activities was assessed using a 'yes/no' response variable.

\section{Assays}

Serum concentrations of insulin-like growth factor I (IGF-I) were determined by radioimmunoassay after $\mathrm{HCl} /$ ethanol precipitation of binding proteins (Nichols Institute Diagnostics, San Juan Capistrano, CA, USA).
Intra-assay, inter-assay and total coefficients of variation were less than $9 \%$ in the concentration range $125-1046 \mu \mathrm{g} / \mathrm{l}$. The assay detection limit was $13.5 \mu \mathrm{g} / \mathrm{l}$. IGF-I values were analysed using age-specific reference ranges and are expressed as standard deviation scores (SDS).

\section{Statistical methods}

Descriptive statistical results are given as means \pm s.D. or 10th to 90th percentile (for skewed distributions), or percentages. Statistical analyses of effects in terms of different outcome variables (changes in mean values over time) were performed by repeated-measurement regression and maximum likelihood estimation. The general structure of the regression model was outcome $=$ function of (visit, country, age at baseline, gender, visit*country) where the variable country was used to test the difference in mean levels between studied countries, and the interaction term visit*country was used to test if these differences had changed or not during the treatment period. The significance level was set to $5 \%$. Age and gender fulfilled as adjustment variables. The within-patient dependency of the data over visits was modelled by assuming unstructured variance-covariance matrixes. Comparisons of mean values at the 2-year visits versus baseline values were performed assuming identity link and a normal distribution (QoL-AGHDA score and VAS score scale variables) or a log link and a Poisson distribution (days of sick leave, days in hospital and number of doctor visits) or a logit link and a binomial distribution (need for assistance with daily activities and subjective improvement). Statistical tests for heterogeneity were performed using one-way ANOVA, $\chi^{2}$ tests, Fisher's exact test (baseline characteristics) or F-tests and/or Walds' criteria (regression analyses). Confidence intervals were calculated assuming Walds' criteria.

The relationship between the change in QoL and change in other variables was calculated using linear and logistic regression.

Analyses were made using SAS software. PROC MIXED and PROC GENMOD were used for repeated measurement regression. PROC GLM and PROC GENMOD were used for linear and logistic regression. 
All reported doctor visits, days in hospital and days on sick leave were standardized to 1 year and comparisons based on these 1-year values.

\section{Results}

\section{Baseline characteristics}

The baseline characteristics of the three cohorts were comparable with respect to gender distribution and the underlying pituitary disease. Mean age at the start of GH replacement was highest in the Swedish cohort (51.1 years compared with 46.6 years in the Dutch cohort and 46.7 years in the German cohort; $P<0.01$ ). Radiotherapy had been performed significantly more frequently in the Dutch $(55.3 \%)$ and Swedish $(37.4 \%)$ patients than in the German patients $(7.1 \%)$. All details about country-specific differences at baseline are given in Table 1.

\section{Dose of growth hormone and levels of IGF-I}

In all cohorts, the mean dose of GH increased during the first year and then stabilized (Table 3). This was associated with an increase in the IGF-I SDS to normal levels after 1 year of GH treatment, again followed by stabilization (Fig. 1). In Sweden and the Netherlands, females received higher doses of GH after 1 and 2 years of treatment. Nevertheless, males had higher mean IGFI levels at baseline and during follow-up. In Germany, males received slightly higher $\mathrm{GH}$ doses than females resulting in even higher mean IGF-I levels.

In addition to these country-specific differences, there were also differences in the mean GH dose depending on the time when GH therapy was started. Mean maintenance dose was $0.40 \mathrm{mg} /$ day in patients who started treatment between 1995 and 1997 and $0.33 \mathrm{mg} /$ day in patients with treatment initiation between 1998 and 2001.

\section{Quality of life and healthcare utilization}

QoL, as assessed using the QoL-AGHDA, significantly improved during 2 years of $\mathrm{GH}$ replacement therapy

Table $3 \mathrm{GH}$ doses during 2 years of $\mathrm{GH}$ replacement therapy in $503 \mathrm{GH}$-deficient adults enrolled in KIMS - the Pfizer International Metabolic Database - in Sweden, The Netherlands and Germany. Values are means \pm S.D.

\begin{tabular}{llll}
\hline & \multicolumn{3}{c}{ GH dose (mg/day) } \\
\cline { 2 - 4 } & Sweden & The Netherlands & Germany \\
\hline First-year visit & & \\
Males & $0.31 \pm 0.17$ & $0.34 \pm 0.16$ & $0.38 \pm 0.23$ \\
Females & $0.37 \pm 0.19$ & $0.47 \pm 0.21$ & $0.36 \pm 0.18$ \\
Second-year visit & & \\
Males & $0.32 \pm 0.21$ & $0.31 \pm 0.20$ & $0.36 \pm 0.27$ \\
Females & $0.39 \pm 0.25$ & $0.52 \pm 0.27$ & $0.35 \pm 0.25$ \\
\hline
\end{tabular}

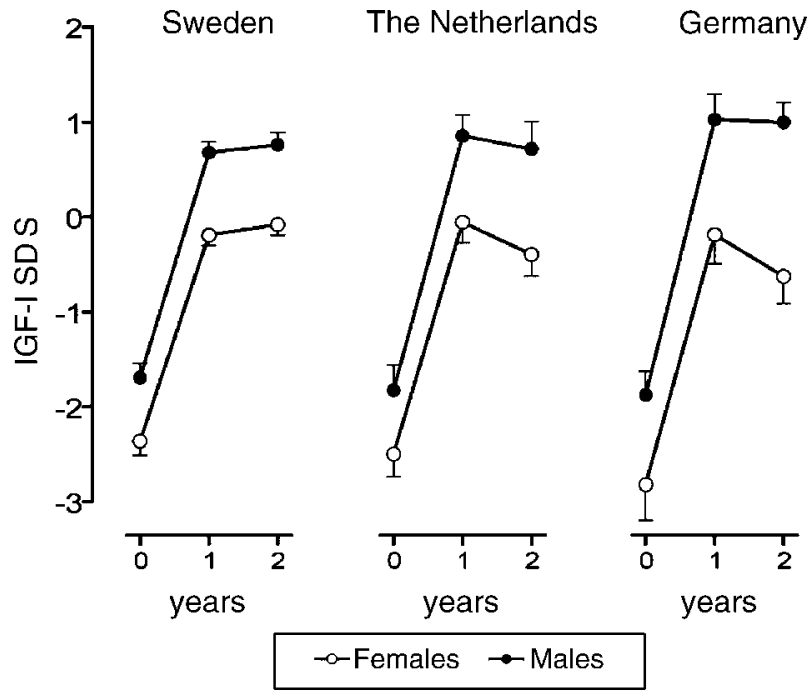

Figure 1 Insulin-like growth factor I (IGF-I) SDS during 2 years of $\mathrm{GH}$ replacement therapy in 258 men and 245 women with GH deficiency enrolled in KIMS - the Pfizer International Metabolic Database - in Sweden, The Netherlands and Germany. Values are given as means \pm S.E.M.

$(P<0.0001)$. Baseline scores were significantly different between the three countries $(P=0.03)$ with the highest values, denoting the lowest baseline QoL, in Dutch patients. Nevertheless, the improvement in QoL during GH replacement was comparable between the three groups (Fig. 2).

In the whole cohort, improvements in QoL-AGHDA scores were significantly related to baseline scores, i.e. patients with the highest scores at baseline indicating the poorest QoL improved most during follow-up $(P=0.0066)$. In all countries, males had a slightly better QoL-AGHDA-score at baseline than females (Sweden: 7.82 vs. 9.59, The Netherlands: 8.87 vs. 11.19 , Germany: 8.97 vs. 9.97). However,

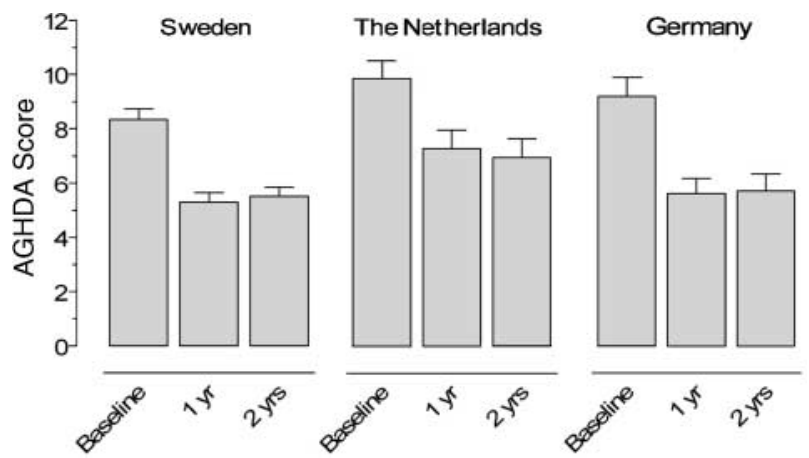

Figure 2 QoL-Assessment in Growth Hormone Deficient Adults (QoL-AGHDA) questionnaire scores during 2 years of GH replacement therapy in 503 adult patients with GHD enrolled in KIMS - the Pfizer International Metabolic Database - in Sweden, The Netherlands and Germany. Values are given as means \pm S.E.M. 
a statistically significant difference in the rate of change between gender was seen neither over all countries $(P=0.28)$ nor when each country was evaluated separately $(P=0.58)$.

The number of doctor visits (excluding visits for routine monitoring of therapy) was significantly different between the three countries at baseline $(P<0.0001)$ and showed a significant overall reduction during $\mathrm{GH}$ treatment $(P<0.0001)$ which, again, was significantly different between the countries $(P=0.005)$ (Table 4$)$. The most significant reduction in doctor visits was seen in the German population, which, at baseline, showed the highest number of doctor visits (mean 9.5 visits/year). With a mean of 3.2 visits/year, the Swedish patients had the lowest number of doctor visits at baseline and subsequently had the smallest percentage reduction during GH replacement. This still, however, reached statistical significance $(P<0.05)$.

The number of days in hospital were slightly but not significantly different between the countries at baseline (Germany 11.1 days/year, the Netherlands 7.3 days/ year, Sweden 3.8 days/year, $P=0.06$ ) and was also significantly reduced (by $83 \% ; P<0.0001$ ) during $\mathrm{GH}$ replacement. There were no country-specific differences during follow-up. The same was true for the number of days of sick leave (baseline 30.6 days/year (Germany), 22.2 days/year (the Netherlands), and 29.7 days/year (Sweden) respectively, reduction of $63 \% ; P=0.0004$ ).

Apart from these country-specific differences, healthcare utilization at baseline was significantly related to the underlying diagnosis which caused GHD. The number of days in hospital was highest in the nonfunctioning pituitary adenoma group (mean 8.1 days) and lowest in the idiopathic GHD group (mean 2.5 days). The number of doctor visits was highest in the craniopharyngioma group (mean 10.2) and again lowest in the idiopathic GHD group (mean 5.8). No significant differences were seen between the various aetiologies of GHD with respect to changes of healthcare utilization during follow-up.

\section{Patient-reported outcomes}

After 2 years of GH treatment, subjective improvements in general well-being were reported by $79.0 \%$ of the Swedish patients, by $75.8 \%$ of the Dutch patients and by $75.0 \%$ of the German patients (Fig. 3). The reported subjective improvement was not significantly different between the three countries.

At baseline, the VAS scores for physical activity during leisure time were higher in the Swedish patients (41.0) than in the German (37.6) and Dutch (27.1) patients $(P$ for heterogeneity $<0.0001)$. No country difference was seen for baseline satisfaction with physical activity. During GH replacement therapy, both parameters improved significantly (VAS score for physical activity: +5.0, VAS score for satisfaction with physical activity $+7.9, P<0.0001)$, with similar improvements in the three countries.

At baseline, $12.9 \%$ of the Swedish patients, $24.9 \%$ of the Dutch patients and $13.2 \%$ of the German patients needed assistance with daily activities. These country differences were statistically significant $(P=0.01)$. In all countries, the percentage of patients needing assistance was higher in female than in male patients (Sweden, 17.8\% versus 6.4\%; The Netherlands, $42.3 \%$ versus $7.0 \%$; Germany, $14.2 \%$ versus $12.2 \%$ ). In all countries, the need for assistance with daily activities showed a slight, but not significant, decrease during $\mathrm{GH}$ replacement therapy $(-14 \%)$.

\section{Relationship between Quality of Life- Assessment in Growth Hormone Deficient Adults scores and other variables}

The changes in QoL-AGHDA scores after 2 years of GH replacement are significantly related to the change in leisure-time physical activity, satisfaction with physical activity, and subjective improvement in general wellbeing (Table 5). These results were pooled, as estimates were relatively homogenous between the three countries.

No association was found between the change in QoLAGHDA scores and changes in healthcare utilization, i.e. number of doctor visits, number of hospital days, and days of sick leave.

\section{Discussion}

The present study confirms that GH treatment in adults with GHD is associated with a significant improvement in QoL, in conjunction with a significant reduction in healthcare utilization. Such beneficial changes have

Table 4 Number of doctor visits during 2 years of GH replacement therapy in $503 \mathrm{GH}$-deficient adults enrolled in KIMS - the Pfizer International Metabolic Database - in Sweden, The Netherlands and Germany.

\begin{tabular}{lcccr}
\hline & Baseline & Second-year visit & Percentage change & \multicolumn{1}{c}{$\boldsymbol{P}$ value } \\
\hline Swedish cohort & $3.2(2.7-3.8)$ & $2.6(2.2-3.1)$ & $-19.7(-34.7$ to -1.4$)$ & 0.037 \\
Dutch cohort & $7.0(5.6-8.8)$ & $3.3(2.1-5.0)$ & $-53.9(-71.4$ to -25.7$)$ & 0.002 \\
German cohort & $9.5(7.3-12.3)$ & $4.1(3.1-5.5)$ & $-56.7(-70.0$ to -37.6$)$ & $<0.0001$ \\
\hline
\end{tabular}

To account for the impact of gender and age, the results have been adjusted and are expressed for 45 -year-old patients at baseline and assuming $50 \%$ males and $50 \%$ females (mean values, with $95 \%$ confidence intervals in parentheses). 


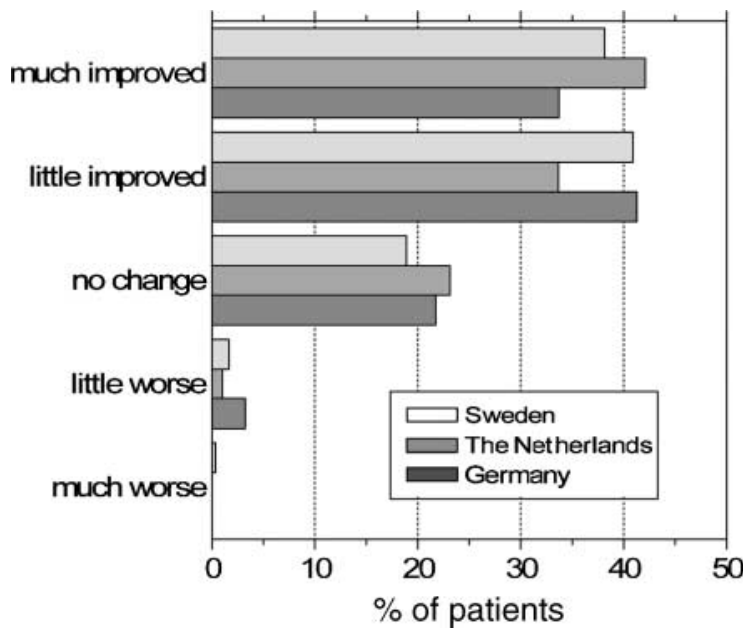

Figure 3 Patient-reported subjective improvements during 2 years of $\mathrm{GH}$ replacement therapy in 503 adult patients with GH deficiency enrolled in KIMS - the Pfizer International Metabolic Database - in Sweden, The Netherlands and Germany.

been reported previously in multinational (14) and single-country (15) analyses. In addition, differences in QoL between several European populations have been reported in the general population as well as in patients with GHD (19-21). The present study provides a comparative analysis of the course of QoL and healthcare utilization during $\mathrm{GH}$ replacement therapy in three well-defined European populations.

The doses of GH and the increases in IGF-I levels were similar in each country. In all populations investigated, females had lower IGF-I levels than males, which has been previously reported in several other studies (2224). From these reports it is well known that women require higher doses of GH than men. In fact, to reach the same IGF-I concentrations, women need almost a $20 \%$ higher $\mathrm{GH}$ dose than men, and a $125 \%$ higher dose is needed in women receiving oral oestrogens $(25$, 26). Therefore, the results of the present study indicate that in all countries investigated, women with GHD were not receiving the optimum replacement dose of GH. This is most striking in the German cohort, where males received even higher doses than females, but, interestingly, also applies to the Dutch cohort, where females received higher doses than in the other countries.

Baseline characteristics, including the underlying pituitary disorders, were very similar between the countries, with the exception that radiotherapy was used significantly less often in Germany. Slight, but significant, between-country differences at baseline were seen for parameters such as QoL, physical activity during leisure time, assistance with daily activities and number of doctor visits. The differences in doctor visits at baseline reflect the officially reported national data for each country with a mean number of approximately nine visits in Germany, six visits in The Netherlands, and three visits in Sweden each year for the last 5 years (27-29).

Despite a similar mean age of the three populations and very similar percentages of other replaced hormones, striking differences were found in the percentage of female patients receiving oestrogen replacement therapy. Since sex-steroid replacement has been found to be associated with outcome in hypopituitary patients, this fact needs further investigation (30).

Despite these differences between the three populations at baseline, $\mathrm{OoL}$ and healthcare utilization improved by a similar extent in each cohort during GH replacement therapy. Similar results have been reported from another multinational study (21). The QoL-AGHDA-scores after 2 years of treatment seem still to be higher than in the normal population.

Table 5 Change in QoL-Assessment in Growth Hormone Deficient Adults (QoL-AGHDA) questionnaire scores and some Patient Life Situation Form scores between baseline and 2 years of GH treatment in $503 \mathrm{GH}$-deficient adults enrolled in KIMS - the Pfizer International Metabolic Database - in Sweden, The Netherlands and Germany.

\begin{tabular}{lccccccc}
\hline $\begin{array}{c}\text { Change in } \\
\text { QoL-AGHDA } \\
\text { score }\end{array}$ & $\begin{array}{c}\text { Change in } \\
\text { physical } \\
\text { activity VAS } \\
\text { score }\end{array}$ & $\begin{array}{c}\text { Change in } \\
\text { satisfaction } \\
\text { with physical } \\
\text { activity VAS } \\
\text { score }\end{array}$ & $\begin{array}{c}\text { Percentage of } \\
\text { patients who } \\
\text { reported } \\
\text { improvement }\end{array}$ & $\begin{array}{c}\text { Percentage of } \\
\text { patients no } \\
\text { longer requir- } \\
\text { ing assistance }\end{array}$ & $\begin{array}{c}\text { Change in } \\
\text { number of } \\
\text { doctor visits }\end{array}$ & $\begin{array}{c}\text { Change in } \\
\text { number of } \\
\text { hospital days }\end{array}$ & $\begin{array}{c}\text { Change in } \\
\text { days of sick } \\
\text { leave }\end{array}$ \\
\hline $\begin{array}{c}0 \text { (no change) } \\
(n=133)\end{array}$ & $-1.8(2.4)$ & $-0.5(2.8)$ & $56.4(46.9-65.6)$ & $1.4(0.3-5.8)$ & $-2.3(0.8)$ & $-5.0(2.6)$ & $-23.3(13.1)$ \\
$-\begin{array}{c}1 \text { to }-3 \\
(n=109)\end{array}$ & $3.3(2.7)$ & $6.6(3.1)$ & $76.4(66.6-84.0)$ & $4.9(2.1-11.1)$ & $-4.3(0.8)$ & $-11.3(2.7)$ & $-24.7(13.9)$ \\
$-\begin{array}{c}4 \text { to }-7 \\
(n=103)\end{array}$ & $12.0(2.7)$ & $12.4(3.1)$ & $86.2(77.5-91.9)$ & $10.1(5.3-18.5)$ & $-4.1(0.8)$ & $-9.0(2.7)$ & $-22.7(14.5)$ \\
$-\begin{array}{c}8 \text { to }-18 \\
(n=86)\end{array}$ & $12.0(2.9)$ & $20.1(3.4)$ & $90.0(82.0-95.7)$ & $9.7(4.7-19.0)$ & $-3.6(0.9)$ & $-3.2(2.8)$ & $-16.0(16.1)$ \\
$\begin{array}{c}\text { Trend over } \\
\text { categories }\end{array}$ & $P<0.0001$ & $P<0.0001$ & $P<0.0001$ & $P=0.002$ & $P=0.25$ & $P=0.55$ & $P=0.7$ \\
\hline
\end{tabular}

Data are given as mean and S.E.M. or as mean and $95 \% \mathrm{Cl}$.

${ }^{1}$ Total $431 ; 72$ missing due to due to lack of data at either baseline or 2 years or both.

${ }^{2}$ Among those working full- or part-time at both the baseline and 2-year visit $(n=221)$ 
This, however, can only be evaluated for the Swedish population, where normative data for the QoL-AGHDA are currently available $(17,18)$.

According to previous reports $(3,21,31)$, most of the improvements in QoL during GH replacement therapy were observed during the first year of treatment and these improvements were maintained during follow-up. There was a significant association between baseline QoL and improvement in QoL during follow-up, i.e. better improvements were seen in patients with poorer QoL at baseline.

Improvements in QoL seem to be related to physical activity, satisfaction with physical activity, patientreported improvement in health and a reduced requirement for assistance with daily activities, but not to changes in healthcare utilization. Therefore, the data indicate that QoL is not a good predictor of reduction in healthcare use in this population.

It is well-established that exercise capacity and physical activity are improved following GH replacement in adults $(7,32)$. The improvement is probably multifactorial, involving improved cardiac function as well as increased muscle mass and strength $(7,32,33)$. An increase in oxygen transport capacity due to a stimulatory effect of IGF-I on erythropoiesis may also contribute to increased physical activity (34).

Furthermore, adults with GHD have previously been shown to experience improvements in psychological functioning and QoL during GH replacement therapy $(3,35,36)$. This has also been shown, using the QoLAGHDA questionnaire, in patients in KIMS treated for up to 3 years with $\mathrm{GH}(14,15,22)$.

In addition, some studies have shown improvements in cognitive function with $\mathrm{GH}$ replacement therapy $(1,12,37)$. Effects on psychological functioning may be mediated by direct $\mathrm{GH}$ effects on the brain, as well as indirectly through effects on body composition and cardiovascular parameters. GH can cross the bloodbrain barrier, and the GH receptors found in the choroid plexus have been proposed as the site of passage of $\mathrm{GH}$ into the central nervous system (37). GH has been shown to influence neurotransmitters known to affect mood, such as dopamine and $\beta$-endorphin $(38,39)$.

\section{Conclusion}

This study provides a detailed comparative analysis of the effects of GH replacement therapy in GH-deficient adults in three European countries, which have a similar cultural background and healthcare policy. Under the conditions of clinical practice, there were some significant differences between the characteristics of the patient populations receiving GH replacement therapy and between the strategies of hormone replacement therapies. However, the beneficial effects of GH replacement on QoL, patient-reported outcomes and healthcare utilization were essentially similar. These results provide important information for further socioeconomic evaluations of GH-replacement therapy in the healthcare environments of Western European countries.

\section{References}

1 Arwert LI, Deijen JB, Muller M \& Drent ML. Long-term growth hormone treatment preserves GH-induced memory and mood improvements: a 10-year follow-up study in GH-deficient adult men. Hormones and Behaviour 200547 343-349.

2 Bengtsson BA, Eden S, Lonn L, Kvist H, Stokland A, Lindstedt G, Bosaeus I, Tolli J, Sjostrom L \& Isaksson OG. Treatment of adults with growth hormone $(\mathrm{GH})$ deficiency with recombinant human GH. Journal of Clinical Endocrinology and Metabolism 199376 309-317.

3 Burman P, Broman JE, Hetta J, Wiklund I, Erfurth EM, Hagg E \& Karlsson FA. Quality of life in adults with growth hormone $(\mathrm{GH})$ deficiency: response to treatment with recombinant human $\mathrm{GH}$ in a placebo-controlled 21-month trial. Journal of Clinical Endocrinology and Metabolism $1995 \mathbf{8 0} 3585-3590$.

4 Colao A, di Somma C, Pivonello R, Cuocolo A, Spinelli L, Bonaduce D, Salvatore M \& Lombardi G. The cardiovascular risk of adult GH deficiency (GHD) improved after GH replacement and worsened in untreated GHD: a 12-month prospective study. Journal of Clinical Endocrinology and Metabolism 200287 1088-1093.

5 Cuneo RC, Judd S, Wallace JD, Perry-Keene D, Burger H, Lim-Tio S, Strauss B, Stockigt J, Topliss D, Alford F, Hew L, Bode H, Conway A, Handelsman D, Dunn S, Boyages S, Cheung NW \& Hurley D. The Australian Multicenter Trial of Growth Hormone (GH) Treatment in GH-Deficient Adults. Journal of Clinical Endocrinology and Metabolism 199883 107-116.

6 Cuneo RC, Salomon F, Watts GF, Hesp R \& Sonksen PH. Growth hormone treatment improves serum lipids and lipoproteins in adults with growth hormone deficiency. Metabolism $1993 \mathbf{4 2}$ 1519-1523.

7 Cuneo RC, Salomon F, Wiles CM, Hesp R \& Sonksen PH. Growth hormone treatment in growth hormone-deficient adults. II. Effects on exercise performance. Journal of Applied Physiology 199170 695-700.

8 de Boer H, Blok GJ, Voerman B, Derriks P \& van der Veen E. Changes in subcutaneous and visceral fat mass during growth hormone replacement therapy in adult men. International Journal of Obesity and Related Metabolic Disorders 199620 580-587.

9 Gotherstrom G, Svensson J, Koranyi J, Alpsten M, Bosaeus I, Bengtsson B \& Johannsson G. A prospective study of 5 years of GH replacement therapy in $\mathrm{GH}$-deficient adults: sustained effects on body composition, bone mass, and metabolic indices. Journal of Clinical Endocrinology and Metabolism 200186 4657-4665.

10 Hoffman AR, Kuntze JE, Baptista J, Baum HB, Baumann GP, Biller BM, Clark RV, Cook D, Inzucchi SE, Kleinberg D, Klibanski A, Phillips LS, Ridgway EC, Robbins RJ, Schlechte J, Sharma M, Thorner MO \& Vance ML. Growth hormone (GH) replacement therapy in adult-onset gh deficiency: effects on body composition in men and women in a double-blind, randomized, placebocontrolled trial. Journal of Clinical Endocrinology and Metabolism $2004892048-2056$.

11 Johannsson G, Rosen T, Bosaeus I, Sjostrom L \& Bengtsson BA. Two years of growth hormone $(\mathrm{GH})$ treatment increases bone mineral content and density in hypopituitary patients with adultonset GH deficiency. Journal of Clinical Endocrinology and Metabolism $1996812865-2873$.

12 Oertel H, Schneider HJ, Stalla GK, Holsboer F \& Zihl J. The effect of growth hormone substitution on cognitive performance in adult patients with hypopituitarism. Psychoneuroendocrinology 200429 839-850.

13 Shalet SM, Shavrikova E, Cromer M, Child CJ, Keller E, Zapletalova J, Moshang T, Blum WF, Chipman JJ, Quigley CA \& Attanasio AF. 
Effect of growth hormone (GH) treatment on bone in postpubertal GH-deficient patients: a 2-year randomized, controlled, doseranging study. Journal of Clinical Endocrinology and Metabolism $2003 \mathbf{8 8} 4124-4129$.

14 Hernberg-Stahl E, Luger A, Abs R, Bengtsson BA, FeldtRasmussen U, Wilton P, Westberg B \& Monson JP. Healthcare consumption decreases in parallel with improvements in quality of life during $\mathrm{GH}$ replacement in hypopituitary adults with $\mathrm{GH}$ deficiency. Journal of Clinical Endocrinology and Metabolism 2001 86 5277-5281.

15 Svensson J, Mattsson A, Rosen T, Wiren L, Johannsson G, Bengtsson BA \& Koltowska Haggstrom M. Three-years of growth hormone $(\mathrm{GH})$ replacement therapy in $\mathrm{GH}$-deficient adults: effects on quality of life, patient-reported outcomes and healthcare consumption. Growth Hormone and IGF Research 200414 207-215.

16 McKenna SP, Doward LC, Alonso J, Kohlmann T \& Niero M. The QoL-AGHDA: an instrument for the assessment of quality of life in adults with growth hormone deficiency. Quality of Life Research $19998373-383$.

17 Johannsson G, Mattsson AF, Koltowska-Haggstrom M \& Monson JP. Long-Term Growth Hormone Replacement (GHR) in Hypopituitary Adults with Growth Hormone Deficiency (GHD) Leads towards Normalization in Quality of Life $(\mathrm{QoL})$, Measured by Quality of Life Assessment of Growth Hormone Deficiency in Adults (QoL-AGHDA) Instrument In: ENDO 2005 San Diego: The Endocrine Society, 2005.

18 Wiren L, Whalley D, McKenna S \& Wilhelmsen L. Application of a disease-specific, quality-of-life measure (QoL-AGHDA) in growth hormone-deficient adults and a random population sample in Sweden: validation of the measure by rasch analysis. Clinical Endocrinology (Oxf) 200052 143-152.

19 Blum WF, Shavrikova EP, Edwards DJ, Rosilio M, Hartman ML, Marin F, Valle D, van der Lely AJ, Attanasio AF, Strasburger CJ, Henrich G \& Herschbach P. Decreased quality of life in adult patients with growth hormone deficiency compared with general populations using the new, validated, self-weighted questionnaire, questions on life satisfaction hypopituitarism module. Journal of Clinical Endocrinology and Metabolism 200388 4158-4167.

20 Koltowska-Haggstrom M, Hennessy S, Mattsson AF, Monson JP \& Kind P. Quality of life assessment of growth hormone deficiency in adults (QoL-AGHDA): comparison of normative reference data for the general population of England and Wales with results for adult hypopituitary patients with growth hormone deficiency. Hormone Research 200564 46-54.

21 Rosilio M, Blum WF, Edwards DJ, Shavrikova EP, Valle D, Lamberts SW, Erfurth EM, Webb SM, Ross RJ, Chihara K, Henrich G, Herschbach P \& Attanasio AF. Long-term improvement of quality of life during growth hormone $(\mathrm{GH})$ replacement therapy in adults with GH deficiency, as measured by questions on life satisfactionhypopituitarism (QLS-H). Journal of Clinical Endocrinology and Metabolism 200489 1684-1693.

22 Bengtsson BA, Abs R, Bennmarker H, Monson JP, FeldtRasmussen U, Hernberg-Stahl E, Westberg B, Wilton P \& Wuster C. The effects of treatment and the individual responsiveness to growth hormone $(\mathrm{GH})$ replacement therapy in $665 \mathrm{GH}$-deficient adults. KIMS Study Group and the KIMS International Board. Journal of Clinical Endocrinology and Metabolism 199984 39293935.

23 Drake WM, Howell SJ, Monson JP \& Shalet SM. Optimizing gh therapy in adults and children. Endocrine Reviews 200122 $425-450$.
24 Mukherjee A, Monson JP, Jonsson PJ, Trainer PJ \& Shalet SM. Seeking the optimal target range for insulin-like growth factor I during the treatment of adult growth hormone disorders. Journal of Clinical Endocrinology and Metabolism $2003 \mathbf{8 8}$ $5865-5870$.

25 Burman P, Johansson AG, Siegbahn A, Vessby B \& Karlsson FA. Growth hormone (GH)-deficient men are more responsive to GH replacement therapy than women. Journal of Clinical Endocrinology and Metabolism 199782 550-555.

26 Cook DM, Ludlam WH \& Cook MB. Route of estrogen administration helps to determine growth hormone (GH) replacement dose in GH-deficient adults. Journal of Clinical Endocrinology and Metabolism 199984 3956-3960.

27 Federal health monitoring system. Federal Statistical Office and Robert-Koch-Institut. http//www.gbe-bund.de.

28 Socialstyrelsen. The national board of health and welfare. http// statline.cbs.nl.

29 Statistics Netherlands. http//www.sos.se.

30 Tomlinson JW, Holden N, Hills RK, Wheatley K, Clayton RN, Bates AS, Sheppard MC \& Stewart PM. Association between premature mortality and hypopituitarism, West Midlands Prospective Hypopituitary Study Group. Lancet 2001357 425-431.

31 Wiren L, Bengtsson BA \& Johannsson G. Beneficial effects of longterm GH replacement therapy on quality of life in adults with GH deficiency. Clinical Endocrinology (Oxf) 199848 613-620.

32 Jorgensen JO, Vahl N, Hansen TB, Thuesen L, Hagen C \& Christiansen JS. Growth hormone versus placebo treatment for one year in growth hormone deficient adults: increase in exercise capacity and normalization of body composition. Clinical Endocrinology (Oxf) 199645 681-688.

33 Cuneo RC, Salomon F, Wiles CM \& Sonksen PH. Skeletal muscle performance in adults with growth hormone deficiency. Hormone Research 199033 (Suppl 4) 55-60.

34 Christ ER, Cummings MH, Westwood NB, Sawyer BM, Pearson TC, Sonksen PH \& Russell-Jones DL. The importance of growth hormone in the regulation of erythropoiesis, red cell mass, and plasma volume in adults with growth hormone deficiency. Journal of Clinical Endocrinology and Metabolism 199782 2985-2990.

35 McGauley GA. Quality of life assessment before and after growth hormone treatment in adults with growth hormone deficiency. Acta Paediatrica Scandinavia Supplement 1989356 70-74.

36 Sartorio A, Molinari E, Riva G, Conti A, Morabito F \& Faglia G. Growth hormone treatment in adults with childhood onset growth hormone deficiency: effects on psychological capabilities. Hormone Research $1995 \mathbf{4 4} 6-11$.

37 Lai ZN, Emtner M, Roos P \& Nyberg F. Characterization of putative growth hormone receptors in human choroid plexus. Brain Research $1991546222-226$.

38 Burman P, Hetta J, Wide L, Mansson JE, Ekman R \& Karlsson FA. Growth hormone treatment affects brain neurotransmitters and thyroxine. Clinical Endocrinology (Oxf) 199644 319-324.

39 Johansson JO, Larson G, Andersson M, Elmgren A, Hynsjo L, Lindahl A, Lundberg PA, Isaksson OG, Lindstedt S \& Bengtsson BA. Treatment of growth hormone-deficient adults with recombinant human growth hormone increases the concentration of growth hormone in the cerebrospinal fluid and affects neurotransmitters. Neuroendocrinology 199561 57-66.

Received 15 December 2005

Accepted 23 February 2006 